\title{
GPR Examination of Multi-Year Seasonal Storm Impacts on Subsurface Depositional Architectures on a Beach in Grand Marais, MI
}

The shallow subsurface of Grand Marais headland beach, located along the southern shore of Lake Superior, Michigan, was imaged using ground penetrating radar (GPR) to determine how seasonal storm impacts are manifested in subsurface depositional architectures. This study was designed to evaluate the implications of the 1883 emplacement of a jetty system that allows for accumulation of sand from the westerly Grand Sable dunes, which would otherwise be transported further east as a result of longshore drift. Due to the jetty and previous research, there is an indication that the beach is growing.

GPR data were acquired during spring, fall, and winter seasons over the course of two consecutive years (2016-2017) to determine if and where subsurface structures are being preserved. Images were subsequently used to determine the annual changes in beach architecture. Emphasis was placed on evaluating the nature of unconformities, formed by strong winter storms, given their suitability for subsurface correlation.

The $250 \mathrm{MHz}$ and $500 \mathrm{MHz}$ GPR setups mapped lake-ward-sloping sediment packages, interpreted as former foreshore deposits bounded by horizontal units, which were the product of aeolian processes. The data reveals correlations between sediment packages located on three different shore-perpendicular survey lines, which were connected by a shore-parallel tie line. Features encountered in the data are depositional onlap and erosional truncation. The latter is the result of the seasonal storm impacts on the beach and/or changes in sediment availability.

The presence of the jetty has allowed for preservation of the shoreline facies, which would be minimal under natural erosional conditions. The patterns detected from the data provides insightful information on the effects of the seasonal storms on shoreline dynamics. Further seasonal data collection, would augment our knowledge of the depositional and erosional cyclic processes that are responsible for shoreline growth. 